\title{
Group A streptococcal endometritis: Report of an outbreak and review of the literature
}

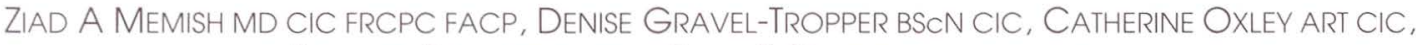 BALDWIN TOYE MD FRCPC, GARY E GARBER MD FRCPC FACP}

\begin{abstract}
ZA Memish, D Gravel-Tropper, C OxLey, B Toye, GE Garber. Group A streptococcal endometritis: Report of an outbreak and review of the literature. Can J Infect Dis 1994;5(6):276-281. Two cases of group A streptococcus (GAS) postpartum endometritis were diagnosed within $24 \mathrm{~h}$ following uncomplicated vaginal delivery. Investigation by the infection control service identified all 10 obstetric personnel who performed any invasive procedure on both cases. These personnel were questioned about a recent history of sore throat, skin lesions, vaginal or rectal symptoms. Throat and rectal cultures were obtained for GAS from all 10 personnel. A carrier was identified among the personnel screened. This nurse was removed from direct patient care and treated with a two-week course of oral clindamycin and rifampin with documentation of carrier eradication of GAS at the end of therapy, 30 days, 60 days and six months post-treatment. All three isolated strains were identical by restriction endonuclease analysis and by $\mathrm{M}$ and $\mathrm{T}$ typing. Rapid implementation of infection control measures were successful in arresting this outbreak, with no further cases of GAS occurring in the subsequent year.
\end{abstract}

Key Words: Endometritis, Infection control, Streptococcus pyogenes

\section{Endométrite à streptocoque du groupe A : rapport de deux cas et revue de la littérature}

RÉSUMÉ : Deux cas d'endométrite post-partum à streptocoque du groupe A ont été diagnostiqués à l'intérieur d'une période de 24 heures après des accouchements par voies naturelles. Les recherches effectuées par le service de prévention des infections ont identifié 10 membres du personnel ayant procédé à des examens effractifs chez les deux parturientes. Ces personnes ont été interrogées sur de possibles antécédents récents de maux de gorge, de lésions cutanées ou de symptômes vaginaux ou rectaux. Des cultures de gorge et de selles ont été obtenues pour le dépistage du streptocoque du groupe A auprès des dix personnes examinées. Une porteuse a été identifiée parmi elles. Cette infirmière a été écartée des soins directs aux parturientes et traitées durant deux semaines par clindamycine et rifampin; l'éradication du pathogène a été obtenue chez cette porteuse à la fin du traitement et 30 jours, 60 jours puis six mois après le traitement. Les trois souches isolées étaient identiques selon l'analyse de l'endonucléase de restriction et les typages $\mathrm{M}$ et $\mathrm{T}$. L'application rapide de mesures de lutte contre l'infection a réussi à enrayer cette épidémie, aucun autre cas d'infection à streptocoque du groupe A ne s'étant déclaré au cours de l'année suivante.

Division of Infectious Diseases, Department of Medicine, Ottawa General Hospital and the University of Ottawa; Occupational Health and Safety and Infection Control, Ottawa General Hospital; and Division of Medical Microbiology. Department of Pathology and Laboratory Medicine, University of Ottawa, Ottawa, Ontario

Correspondence and reprints: Dr Ziad A Memish, King Fahad National Guard Hospital, Department of Medicine, PO Box 22490

Riyadh, 11426 Saudi Arabia. Telephone (9661) 2520088 ext 3718, Fax (9661) 2520140

Received for publication November 17, 1993. Accepted May 9, 1994 
$\mathrm{E}$ PIDEMICS OF PUERPERAL SEPSIS DURING THE 16TH TO 19 th centuries were not uncommon and the mortality rate was extremely high (up to $40 \%$ ) (1-3). Puerperal sepsis follows abortion or vaginal delivery when streptococci either colonizing the patient or inadvertently transmitted from medical personnel invade the endometrium, surrounding tissues and blood stream. This may result in complications including pelvic cellulitis, septic pelvic thrombophlebitis, peritonitis or pelvic abscess. In the 20th century, with the advent of antibiotics and improved socioeconomic conditions, the rate and severity of group A streptococcus (GAS) infection have declined, with only sporadic cases and clusters of puerperal infections (4-13). In two studies involving women of childbearing age, the prevalence of vaginal colonization with GAS was less than $1 \%(14,15)$ suggesting that endogenous sources are uncommon and that clustering of cases can usually be traced to a single carrier (5-8,10-13). These carriers are usually health care workers colonized with the organism in the throat, anus, vagina or a skin lesion. The cause of colonization with GAS and, in some cases, subsequent transmission is unknown. A few reports of attempt at GAS carrier eradication have been published. In most of these reports the treatment modality, extent and duration of follow-up varied, giving little information to guide physicians in the management of these carriers.

In our tertiary care centre there are 36 obstetrical beds with over 3675 admissions in 1992. In July 1992, two cases of GAS endometritis were diagnosed within $24 \mathrm{~h}$ of each other, prompting investigation by the infection control service of the hospital. We summarize these two cases and review the literature with respect to possible therapeutic options and infection control response to such an outbreak.

\section{CASE PRESENTATIONS}

Case 1: A 32-year-old woman presented one week postnormal vaginal delivery with fever, chills, nausea and abdominal pain. Her physical examination on admission revealed a temperature of $39^{\circ} \mathrm{C}$ and a tender uterus. The laboratory investigation revealed an elevated white blood cell count of $1.69 \times 10^{4}$ cells $/ \mathrm{mm}^{3}$ and a urine and vaginal culture positive for GAS. She was admitted to hospital with the diagnosis of postpartum endometritis and treated with intravenous ceftizoxime for $48 \mathrm{~h}$, then switched to oral cephalexin. Her symptoms markedly improved and she was discharged from hospital after two days.

Case 2: A 30-year-old woman had fever and abdominal pain four days postnormal vaginal delivery. Physical findings on admission included a fever of $40^{\circ} \mathrm{C}$, a very tender uterus and foul smelling lochia. The laboratory investigation revealed a white blood cell count of $2.49 \times 10^{4}$ cells $/ \mathrm{mm}^{3}$ with urine and vaginal cultures positive for GAS. She was admitted to hospital with the diagnosis of postpartum endometritis and was treated with intravenous ceftizoxime for $48 \mathrm{~h}$ followed by oral cephalexin. After marked improvement she was discharged.

\section{MATERIALS AND METHODS}

Infection control surveillance: Immediately after these two cases were identified, the hospital's infection control service implemented the following measures:

- The two patients were promptly isolated in private rooms with proper skin barrier techniques.

- The charts of the two cases were reviewed to identify all obstetrical care personnel who had performed invasive procedures on both cases. These procedures included: vaginal examination, artificial rupture of membranes or insertion of Foley catheter.

- Obstetrical care personnel who were involved were questioned about a recent history of sore throat, skin lesions, and vaginal or rectal symptoms.

- Throat and rectal swabs for GAs culture were taken from personnel identified in the chart review.

Microbiological methods: Swabs obtained for GAS culture were inoculated onto 5\% sheep blood agar and incubated anaerobically. Colonies that were betahemolytic and suspected to be streptococci were identified as GAS using a latex agglutination test (PathoDx Strep Grouping, Diagnostic Products Corporation, California).

Two methods of typing the GAS isolates were used. In the first method, serological typing for $M$ protein, $T$ protein and opacity factor were carried out at the National Streptococcus Laboratory, Edmonton, Alberta using standard techniques. In the second method, restriction enzyme analysis (REA) was done as follows: isolates of GAS were grown overnight at $37^{\circ} \mathrm{C}$ in $5 \mathrm{~mL}$ of Todd-Hewitt broth. Cells were washed twice with $0.2 \mathrm{M}$ sodium acetate, $\mathrm{pH} 6.0$, and resuspended in $500 \mu \mathrm{L}$ of TE-glucose (100 mM Tris, $10 \mathrm{mM}$ EDTA, 25\% glucose, $\mathrm{pH} 8$ ) containing $50 \mu \mathrm{g}$ of mutanolysin (Sigma). Following a $1 \mathrm{~h}$ incubation at $37^{\circ} \mathrm{C}$, the cells were lysed with $0.5 \%$ sodium dodecyl sulphate and $500 \mu \mathrm{g}$ of proteinase $\mathrm{K}$ for 60 mins. After extraction with phenol-chloroform and ethanol precipitation, total genomic DNA was digested with Hind III or ClaI and separated by agarose gel electrophoresis. Two other clinical strains of GAS not epidemiologically linked to the outbreak strains were used as controls.

\section{RESULTS}

Infection control results: Chart review identified 10 obstetrical care personnel who had performed invasive procedures on both cases. All had surveillance culture for GAS from the throat and rectum; none had any skin lesions. All throat cultures were negative. A nurse who 


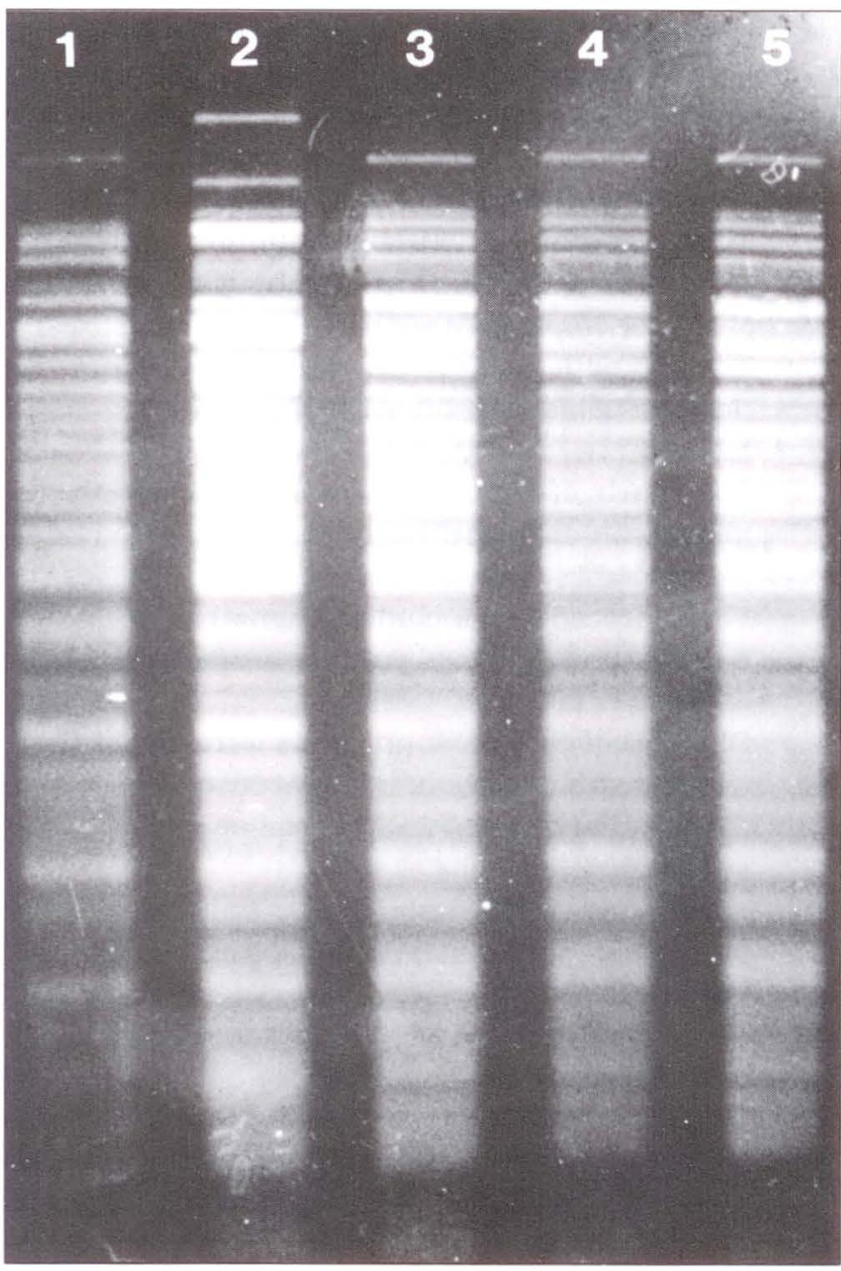

Figure 1) Restriction enzyme analysis patterns following diges tion of extracted DNA with Hind III. Lanes 1 and 2 are control group A streptococcus (GAS) strains that are not epidemiologically linked. Lanes 3 to 5 are the GAS isolates from the two cases and the rectal carrier

performed vaginal examinations on both patients was the only person with a positive anal culture for GAS, and she also gave a history of recent sinus infection. She had received two courses of oral antibiotics in the preceding month (penicillin/cephalosporin, specific drug not recalled). A retrospective chart review was undertaken of all patients who had delivered while the index nurse was on duty during the two weeks before and after the first case was discovered. Of 60 patients identified, four had invasive procedures performed by the same nurse. The four patients remained well. The nurse was removed from direct patient care and a repeat anal swab was still positive for GAS. She was treated with oral clindamycin $300 \mathrm{mg}$ tid and rifampin $600 \mathrm{mg}$ once daily for two weeks with subsequent negative cultures at two weeks, 30 days and six months' follow-up. The nurse returned to regular duty after the first negative culture. No further cases of nosocomial GAS infection have occurred after one year of follow-up.

Microbiological results: All three isolates of GAS (two cases and the carrier) were identical by serological typing and REA. The three strains were identified as M nontypable, T type B3264 and antiopacity factor-positive. Compared with the two control strains, the three GAS isolates also had identical REA patterns following digestion with Hind III (Figure 1) and Clal (data not shown).

\section{DISCUSSION AND REVIEW OF THE LITERATURE}

Background: In the 18th and early 19th centuries, GAS disease was feared because of its severity and high risk of death. Ignaz Semmelweis (16) in 1847 demonstrated that the maternal mortality rate was higher in the division of a hospital staffed by medical staff than in the section run by midwives. This was due to the medical staff's participation in autopsies and failure to decontaminate their hands adequately. He ordered that the hands of medical students be washed in chlorinated lime before examining women. The mortality rate fell from $10 \%$ to $3 \%$, but it was many years before his colleagues accepted these observations. In 1889 in Paris, Pasteur finally documented that puerperal fever was caused by the presence of microorganisms which he described as occurring in chains (17). He found this organism in the lochia, in the uterus and in the blood of cases and was successful in culturing it. In 1933 in England and Wales, 1016 women died of puerperal sepsis. In 1967, the last year of notification of the disease, no deaths occurred among 1175 cases of puerperal fever and pyrexia.

The incidence of postpartum endometritis is between 1 and 4\%. This has not decreased over the past 70 years (18). Postpartum endometritis is usually related to ascension of normal vaginal flora into the endometrium and invasion of the myometrium. This is in contrast to GAS endometritis, in which the source of the organism is usually exogenous, because only $1 \%$ of women are colonized. Historically, this subgroup of endometritis has been referred to as 'puerperal fever' or 'childbed fever'.

Clinical manifestation: GAS endometritis has characteristic clinical features such as rapid onset of a high spiking fever (ie, within two to three days postpartum). The patient looks clinically ill with no localizing physical signs, has clear lochia that shows abundant Grampositive cocci in chains and a slow response to antibiotic therapy with defervescence occurring after $72 \mathrm{~h}$ of treatment $(8,12,13,19)$. Although these characteristics are observed in most cases of GAS endometritis, similar presentations are noted in endometritis due to other etiologies $(20,21)$.

Diagnosis: The problem with identifying precisely the bacterial etiology of endometritis has long been recognized. Swabs passed through the vagina will invariably be contaminated by normal vaginal flora making culture results difficult to interpret. However, the identification of organisms such as GAS, Neisseria gonorrhoeae or Chlamydia trachomatis, which are not considered part 
of normal vaginal or cervical flora, should trigger a specific physician response for treatment in the right clinical setting. Positive blood cultures are also helpful in establishing etiology.

Transmission of GAS and outbreaks: Studies have demonstrated that GAS can spread by direct contact with skin or secretions of infected individuals. Experiments with GAS in military recruits suggested that airborne streptococci are not very infectious and rarely, if ever, cause pharyngitis in susceptible persons $(22,23)$. This does not, however, imply that airborne streptococci cannot cause wound infection.

Most reported outbreaks of GAS infection can be traced to a carrier of the organism (usually rectum, vagina or skin lesion) (6-8,11-13,24-31). Aerosolization is postulated as the major route of transmission $(6,7,11,24,26,27,31)$. Evidence to support this includes: lack of direct contact between a case and a carrier; GAS-positive quantitative air cultures obtained in the presence of a carrier; and occurrence of infection in patients undergoing surgery in rooms recently vacated by a GAS carrier. There have been no reported outbreaks of GAS nosocomial infection where the carriage site was the throat. This suggests that throat cultures alone are insufficient to exclude a possible source.

In our outbreak, the diagnosis of both cases was consistent with postpartum endometritis, which includes: either the isolation of an organism from the endometrium, or purulent drainage from the uterus plus fever, abdominal pain or uterine tenderness (32). The interpretation of bacteriuria (which was present in both cases) in the postpartum patient is difficult because puerperal discharge often contaminates midstream urine samples causing a high number of false-positive specimens (33). Both cases were treated with ceftizoxime because it was the cephalosporin used for empirical therapy of pelvic infections at our hospital.

The investigation carried out by the infection control service revealed that both patients were initially admitted six days apart (for delivery), and they were in different rooms in the same ward. We did not do throat and rectal cultures for GAS on the two cases of endometritis and no screening of other patients was done, but no GAs had been identified over several years in the obstetrical unit. Of the 10 obstetrical care personnel who performed invasive procedures on both cases, only one was found to be colonized with a similar GAS strain in the rectum. The GAS isolated was $\mathrm{M}$ nontypable, $\mathrm{T}$ type B3264 and opacity factor-positive; this is a rare isolate. In one study of 1648 consecutive GAS strains, only $1 \%$ had this typing pattern (34). Thus, the colonized nurse seems likely to have been the source of the outbreak, although the route of transmission is not entirely clear. No breaks in infection control techniques in this nurse's practices were noted.

An investigation by the infection control service should be initiated after two cases of nosocomial GAS postpartum endometritis are identified because this could indicate an outbreak (35). The patients should be placed on wound and skin isolation precautions for $24 \mathrm{~h}$ after starting effective antimicrobials. This should be followed by careful review of the patients' charts and identification of personnel who were involved in their direct care. These personnel should be questioned about practices, about recent history of sore throat, skin lesions or rectal or vaginal symptoms, examined, and surveillance cultures taken from skin (if there are skin lesions present), rectum and vagina. The history and physical examination are important in identifying the possible site of colonization. In many reports the carrier reported symptoms related to the colonization site such as perineal ulcers, chronic diarrhea and external hemorrhoids $(26,28)$. Positive cultures from a health care worker for GAS does not, however, prove a source of the outbreak. Thus, confirmation by serological or DNA typing methods, such as REA, is required. The purpose of the infection control outbreak investigation is not to lay blame but to prevent subsequent cases. This was accomplished in our outbreak, as no new cases have been identified in the subsequent year. In a few published reports, recurrence of the outbreak was traced to colonization of family members of the index case $(6,25,27)$. Thus, surveillance of family members should also be considered. In our outbreak the family members of the carrier nurse were tested and were negative.

If all involved health care workers are screened and are negative, environmental sources should be considered. In one report, a shower head was identified as the source of the outbreak, although only nasal and throat swabs were taken from health care workers (36).

Treatment and follow-up: GAS endometritis is classically treated with penicillin, but clindamycin is also effective. Some authors have suggested routine penicillin prophylaxis to all personnel and patients in the presence of a GAS outbreak $(6,7,26,37,38)$. Such an indiscriminate approach may, however, delay identification of a common source and only temporarily halt rather than extinguish the epidemic if the carrier is incompletely treated. The eradication of GAS carriage in a health care worker is controversial. Failures with penicillin, tetracycline and cephalosporins have been reported $(6,7,11,26)$. Failure with penicillin has been attributed to beta-lactamase production by other organisms in the gastrointestinal tract $(39,40)$. Oral vancomycin, which is not absorbed from the gastrointestinal tract, has also been used, with negative cultures at follow-up of up to two years $(6,7)$. The duration of treatment and follow-up is not standardized, but the health care worker can usually resume working as soon as follow-up cultures are negative. The need for repeat cultures has not been determined, unless new cases are identified. Recurrence as long as one year after the initial outbreak has been reported (30). 
The addition of rifampin to penicillin has proven to be more efficacious in eradicating GAS from the throat $(41,42)$. Clindamycin has been shown to be superior to penicillin in eradicating the GAS carrier state and preventing recurrent infection in selected patients $(43,47)$. Although the combination of rifampin and clindamycin has not been studied, it was effective here as no new cases appeared after one year of follow-up. More data are, however, required to guide physicians in the choice of antibiotics, duration of treatment and frequency of follow-up in the optimal management of GAS carrier transmitters.

\section{REFERENCES}

1. Meleney FL, Zau ZD, Zaytzeff H, Harvey HD. Epidemiologic and bacteriologic investigation of the Sloane Hospital epidemic of hemolytic streptococcus puerperal fever in 1927. Am J Obstet Gynecol 1928:16:180-95.

2. Watson BP. An outbreak of puerperal sepsis in New York City. Am J Obstet Gynecol 1928;16:157-79.

3. Colebrook L. Puerperal infection, 1800-1950. In: Kerr JMN, ed. Historical Review of British Obstetrics and Gynecology. Edinburgh: Livingstone, 1954:202-25.

4. Hill AM. Why be morbid? Paths of progress in the control of obstetric infections, 1931-1960. Med J Aust 1964;1:101-10.

5. McCabe WR, Abrams AA. An outbreak of streptococcal puerperal sepsis. N Engl J Med 1965;272:615-8.

6. McKee WM, Di Caprio JM, Roberts CE, Sherris JC. Anal carriage as the probable source of a streptococcal epidemic. Lancet 1966;ii:1007-9.

7. McIntyre DM. An epidemic of Streptococcus pyogenes puerperal and post-operative sepsis with an unusual carrier site the anus. Am J Obstet Gynecol 1968;101:308-14.

8. Jewett JF, Reid DE, Safon LE, Easterday C. Childbed fever - a continuing entity. JAMA 1968;206:344-50.

9. Mead PB, Ribble JC, Dillon TF. Group A streptococcal puerperal infection. Report of an epidemic. Obstet Gynecol 1968;22:460-4.

10. Tancer ML, McManis JE, Bellotti G. Group A, type 33, beta-hemolytic streptococcal outbreak on a maternity and newborn service. Am J Obstet Gynecol 1969;103:1028-33.

11. Schaffner W, Lefkwitz LB, Goodman JS, Koenig MG. Hospital outbreak of infections with Group A streptococci traced asymptomatic anal carrier. N Engl J Med 1969;280:1224-5.

12. Ledger WJ, Headington J. Group A beta-hemolytic streptococcus. Obstet Gynecol 1972:39:474-82.

13. McGregor J, Ott A, Villard M. An epidemic of "child bed fever'. Am J Obstet Gynecol 1984:150:385-8.

14. Lancefield RC, Hare R. The serological differentiation of pathogenic and non-pathogenic strains of hemolytic streptococci from parturient women. J Exp Med 1935;61:335-49.

15. Willson JR, Bollinger CC, Ledger WJ. The effect of an intrauterine contraception device on the bacterial flora of the endometrial cavity. Am J Obstet Gynecol 1964:90:726-39

16. Semmelweis IF. Childbed fever. (Reprinted from: Semmelweis IF. The etiology, the concept and the prophylaxis of childbed fever. Pest: CA Hartleben's Verlag-Expedition, 1861.) Rev Infect Dis 1981;3:808-11.

17. Rubenstein A. Subtle poison; the puerperal fever controversy in Victorian Britain. Historical Studies
1983;20:420-38.

18. Newton ER, Prihoda TJ, Gibbs RS. A clinical and microbiological analysis of risk factors for puerperal endometritis. Obstet Gynecol 1990;75:402-6.

19. Ogden E, Amstey MS. Puerperal infection due to group A beta-hemolytic streptococcus. Obstet Gynecol 1977:521:53-5.

20. Gibbs RS, Blanco ID. Streptococcal infections in pregnancy. Am J Obstet Gynecol 1981;140:405.

21. Silver RM, Heddleston LN, McGregor JA, Gibbs RS. Life-threatening puerperal infection due to group A streptococci. Obstet Gynecol 1992;79:894-6.

22. Perry WD, Siegel AC, Rammelkamp CH. Transmission of group A streptococci. The role of contaminated dust. Am J Hyg 1957;66:96-101.

23. Rammelkamp CH, Mortimer EA, Wolinsky E. Transmission of streptoccal and staphylococcal infections. Ann Intern Med 1964;60:753-8.

24. Gryska PF, O'Dea AE. Post-operative streptococcal wound infection. JAMA 1970;213:1189-91.

25. Paul SM, Genese C, Spitalny K. Post-operative group A $\beta$-hemolytic streptococcus outbreak with the pathogen traced to a member of a health care worker household. Infect Control Hosp Epidemiol 1990;1 1:643-6.

26. Berkelman RL, Martin D, Graham DR, et al. Streptococcal wound infections caused by a vaginal carrier. JAMA 1982;247:2680-2.

27. Mastro TD, Farley TA, Elliott JA, et al. An outbreak of surgical wound infections due to group A streptococcus carried on the scalp. N Engl J Med 1990;323:968-72.

28. Richman DD, Breton SJ, Goldman DA. Scarlet fever and group A streptococcal surgical wound infection traced to an anal carrier. J Pediatr 1977;90:387-90.

29. Torbet TE, Porter IA. Streptococcus pyogenes infection in a maternity hospital. Health Bull 1969;27:1 1-2.

30. Viglionese A, Nottebart VF, Bodman HA, Platt R. Recurrent group A streptococcal carriage in a health care worker associated with widely separated nosocomial outbreaks. Am J Med 1991;91(Suppl 3B):3295.

31. Stamm WE, Feeley JC, Facklam RR. Wound infection due to group A streptococcus traced to a vaginal carrier. Infect Dis 1978; 138:287-92.

32. Garner JS, Jarvis WR, Emori TG, Horan TC, Hughes JM. CDC definitions for nosocomial infections, 1988. Am J Infect Control 1988; 16:128-40.

33. Stray-Pedersen B, Blakstad M, Bergan T. Bacteriuria in the puerperium: risk factors, screening procedures and treatment programs. Am J Obstet Gynecol 1990; 162:792-7.

34. Maxted WR, Widdowson JP, Fraser CAM, Ball LC, Bassett DC. The use of the serum opacity reaction in the typing of group A streptococci. J Med Microbiol 1973;6:83-90.

35. Mead PB. Prevention and control of nosocomial infections in obstetrics and gynecology. In: Wenzel RP, ed. Prevention and Control of Nosocomial Infections, 2nd edn. Baltimore: Williams and Wilkins, 1993:776-95.

36. Claesson BEB, Claesson ULE. An outbreak of endometritis in a maternity unit caused by spread of group A streptococci from a shower head. J Hosp Infect 1985:6:304-11.

37. Becker C, Resnick G, Shustak S. On the virulence of group A streptococci. Am J Pathol 1973;72:129-36.

38. Geil C, Castel W, Mortimer E. Group A streptococcal infections in newborn nurseries. Pediatrics 1970:46:849-54.

39. Brook I. The role of $\beta$-lactamase-producing bacteria in the persistence of streptococcal tonsilar infection. Rev Infect Dis 1984;6:601-7. 
40. Gastanduy AS, Kaplan EL, Huwe BB, et al. Failure of penicillin to eradicate group A streptococci during an outbreak of pharyngitis. Lancet 1980;ii:498-502.

41. Tanz RR, Shulman ST, Barthel MJ, et al. Penicillin plus rifampin eradicates pharyngeal carriage of group A streptococci. J Pediatr 1985;106:876.

42. Chaudhary S, Bilinsky SA, Hennessy JL, et al. Penicillin $\mathrm{V}$ and rifampin for the treatment of group A streptococcal pharyngitis: a randomized trial of 10 days penicillin vs 10 days penicillin with rifampin during the final four days of therapy. J Pediatr 1985;106:481.

43. Breese BB, Disney FA, Talpey WB, Green J. B-hemolytic streptococcal infection: comparison of penicillin and lincomycin in the treatment of recurrent infections or the carrier state. Am J Dis Child 1969;117:147-52.
44. Massell BF. Prophylaxis of streptococcal infection and rheumatic fever: a comparison of orally administered clindamycin and penicillin. JAMA 1979:241:1589-97.

45. Brook I, Hierkawa R. Treatment of patients with recurrent tonsillitis due to group A beta hemolytic streptococci: prospective randomized study comparing penicillin, erythromycin and clindamycin. Pediatr Res 1984; 18:270A.

46. Brook I, Leyva F. The treatment of the carrier state of group A beta hemolytic streptococci with clindamycin. Chemotherapy 1981;27:360-7.

47. Breese BB, Disney FA, Talpey WB. Beta hemolytic streptococcal illness: comparison of lincomycin, ampicillin and potassium penicillin $\mathrm{G}$ in treatment. Am J Dis Child 1966;112:21-7. 


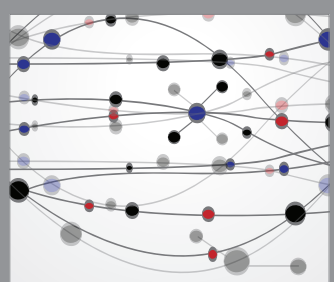

The Scientific World Journal
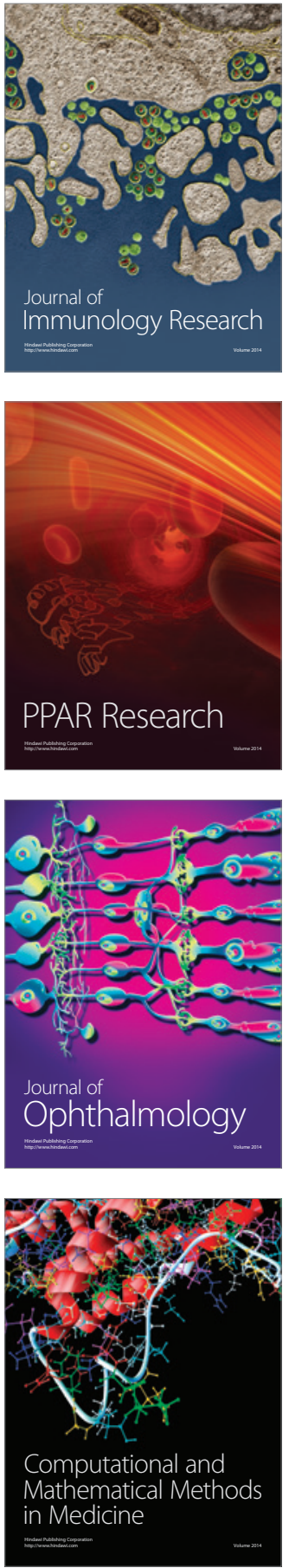

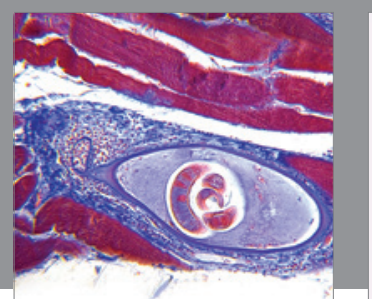

Gastroenterology Research and Practice

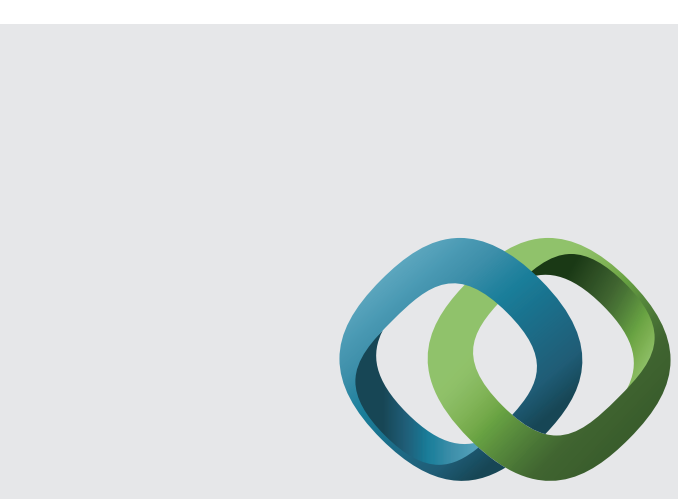

\section{Hindawi}

Submit your manuscripts at

http://www.hindawi.com
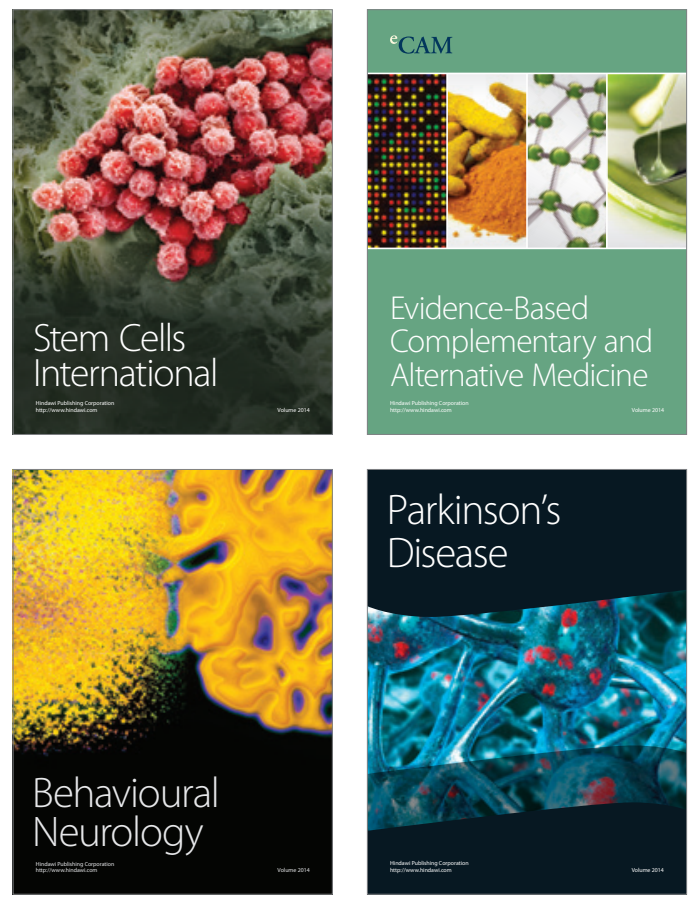
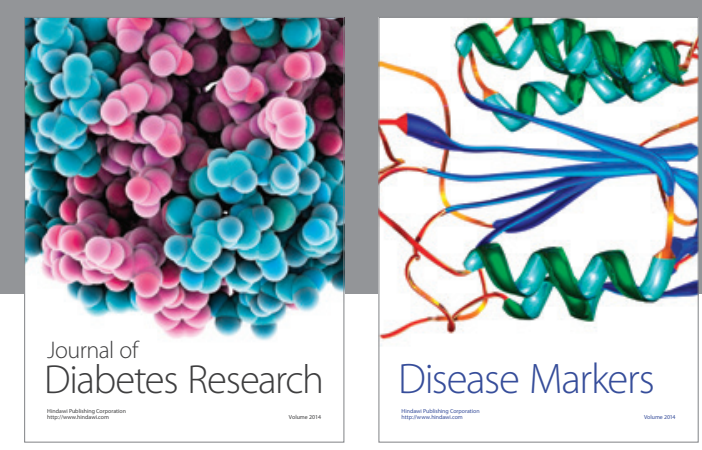

Disease Markers
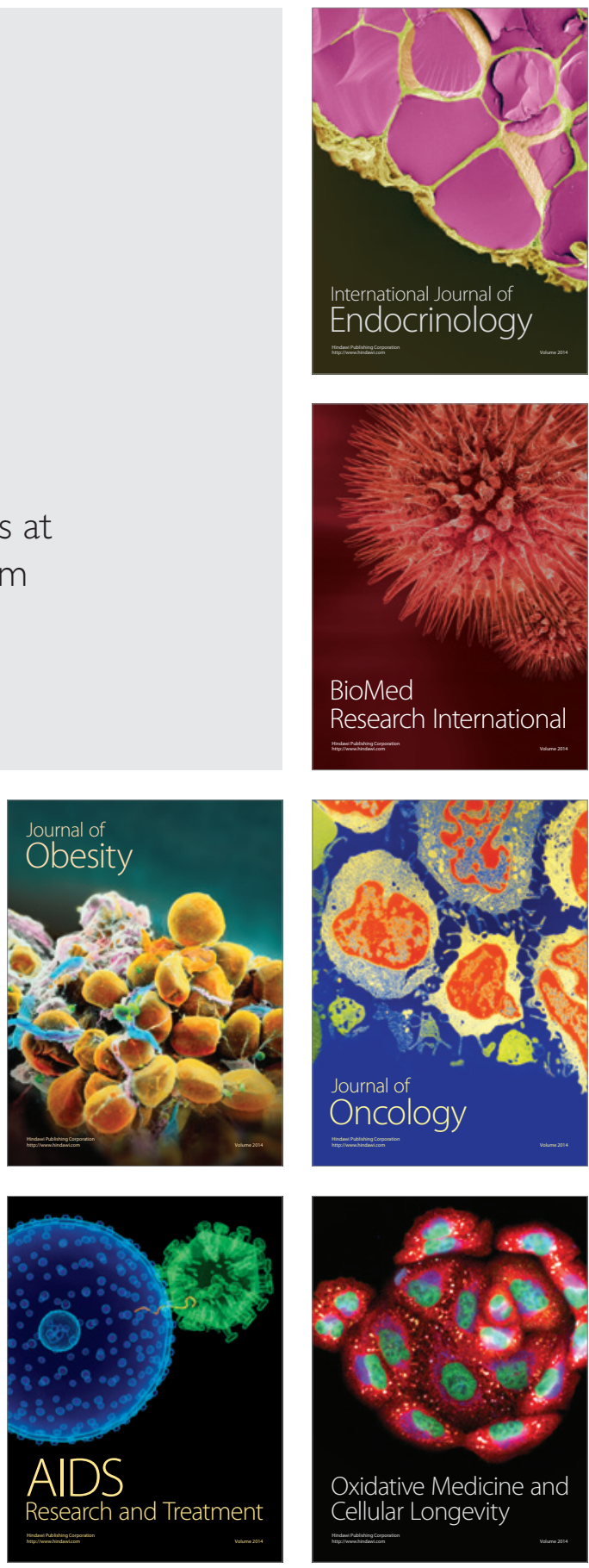